\title{
Recovery of Paretic Lower Extremity Loading Ability and Physical Function in the First Six Months after Stroke
}

\author{
Vicki Stemmons Mercer, PT, PhD ${ }^{1}$, Janet Kues Freburger, PT, $\mathbf{P h D}^{1,2}$, Zhaoyu Yin, $\mathbf{M S}^{3}$, and \\ John S. Preisser, PhD $^{3}$ \\ ${ }^{1}$ Center for Human Movement Science, Department of Allied Health Sciences, University of North \\ Carolina at Chapel Hill, Chapel Hill, North Carolina \\ ${ }^{2}$ Cecil G. Sheps Center for Health Services Research, University of North Carolina at Chapel Hill, \\ Chapel Hill, North Carolina \\ ${ }^{3}$ Department of Biostatistics, University of North Carolina at Chapel Hill, Chapel Hill, North \\ Carolina
}

\begin{abstract}
Objective-To evaluate post-stroke recovery of paretic lower extremity loading, walking ability, and self-reported physical function, and to identify subject characteristics associated with recovery.
\end{abstract}

Design-Inception cohort study, with testing at monthly intervals from one to six months post stroke.

Setting-University medical center and research laboratory.

Participants-Volunteer sample of individuals with first-ever, unilateral, non-cerebellar stroke. A total of 78 individuals underwent screening, and 45 were found to be eligible. Of these, 8 declined participation, 2 were excluded because of deteriorating cognitive status, and 2 were lost to follow-up. The remaining 33 individuals enrolled in the study, and 30 (91\%) completed the study.

Interventions-Not applicable.

Main Outcome Measures-Outcomes were loading of the paretic lower extremity when standing up from a chair (PLEL), self-selected gait speed (GS), and Physical Functioning Index (PFI).

(C) 2014 The American Congress of Rehabilitation Medicine. Published by Elsevier Inc. All rights reserved.

Contact information: Correspondence concerning this article and requests for reprints should be addressed to Vicki S. Mercer, PT, $\mathrm{PhD}$, Division of Physical Therapy, Department of Allied Health Sciences, CB\# 7135, Bondurant Hall, Suite 3022, University of North Carolina at Chapel Hill, Chapel Hill, North Carolina 27599-7135. Fax: (919) 966-3678; Phone: (919) 843-8642; vmercer@med.unc.edu.

Publisher's Disclaimer: This is a PDF file of an unedited manuscript that has been accepted for publication. As a service to our customers we are providing this early version of the manuscript. The manuscript will undergo copyediting, typesetting, and review of the resulting proof before it is published in its final citable form. Please note that during the production process errors may be discovered which could affect the content, and all legal disclaimers that apply to the journal pertain.

Suppliers 
Results-Data analyses using linear mixed models indicated that subjects improved over time for all outcomes. Baseline Fugl-Meyer lower extremity motor scale score was a predictor of immediate post-stroke performance for PLEL and GS, and of recovery rate for PLEL. Factors identified as having significant effects on performance at 6 months post stroke were baseline FuglMeyer lower extremity motor scale score for PLEL and GS, and baseline star cancellation score (from the Behavioral Inattention Test) for PLEL.

Conclusion-Individuals with better baseline paretic lower extremity motor function have better ability to load that extremity during functional activities and faster walking speeds, and these advantages are still present at 6 months post stroke. Individuals with severe visuospatial neglect demonstrate less ability to load the paretic leg during functional activities at 6 months post stroke.

\section{Keywords}

stroke; recovery of function; gait

Stroke is a major cause of long-term disability worldwide. ${ }^{1,2}$ Of the more than 795,000 people in the United States who have a stroke each year, ${ }^{2}$ approximately $50 \%$ still have some degree of hemiparesis and $30 \%$ are unable to walk without assistance six months after the event. ${ }^{2,3}$ An understanding of patterns of recovery over time is important for both clinical practice and research. ${ }^{4,5}$ In the context of stroke rehabilitation, this information facilitates realistic goal-setting and can guide decision-making about timing, type, and setting of the interventions provided. ${ }^{5-8}$

Several studies suggest that the vast majority of stroke survivors experience some degree of spontaneous neurological recovery in the first weeks after stroke, and that the timing of onset and rate of this early recovery are predictive of long-term outcomes. ${ }^{6,9}$ The earlier improvement begins, and the more rapid the initial rate of improvement, the better the longterm outcome ${ }^{6}$ Clinical measures of self-care abilities, when administered in the first week or two after stroke, presumably reflect stroke severity and the extent of this early recovery. ${ }^{10,11}$

Although research has shown that most stroke survivors demonstrate some degree of recovery over time, ${ }^{4,6}$ patterns of recovery are not well understood. Previous studies have differed widely in terms of patient characteristics, measurements, timing of post-stroke evaluations, and outcomes. Most studies have used gross measures of activities of daily living (ADL), such as the Barthel Index or the Functional Independence Measure, ${ }^{8,12-14}$ or of ambulation ability, such as Functional Ambulation Categories, ${ }^{5,15}$ as outcomes. These measures lack sensitivity and may demonstrate ceiling effects in individuals with mild stroke. ${ }^{4}$

Another important consideration in research on functional recovery after stroke is the distinction between improvements in function that result from changes in underlying impairments and those that reflect behavioral compensation. ${ }^{6,9}$ For example, an individual with post-stroke hemiparesis may achieve functional improvement as indicated by decreased time to perform a motor task such as transitioning from a supine to a sitting position. The faster time may reflect true recovery, i.e., improved ability to move the paretic limbs, but 
also may result from increased reliance on the non-paretic limbs. Compensatory movement strategies may be difficult to detect without examination of the kinetics and kinematics of the movement patterns. ${ }^{6,9}$

In the present study, the ability to bear weight through, or "load", the paretic lower extremity during the task of standing up from a chair (sit-to-stand; STS) was assessed monthly from 1 to months after stroke. Lower extremity loading during STS is highly symmetrical in individuals without pathology, as evidenced by equal peak values for dominant and non-dominant lower extremities reported in studies of both younger ${ }^{16}$ and older ${ }^{17}$ adults. Because behavioral compensation after stroke typically involves greater reliance on the non-paretic as compared to the paretic lower extremity, ${ }^{18,19}$ the ability to load the paretic lower extremity should reflect recovery rather than compensation. Other outcomes in the present study were self-selected gait speed (GS) ${ }^{20}$ and the MOS Short Form-36 (SF-36) Physical Functioning Index (PFI) ${ }^{21}$ score. purpose of the study was to evaluate changes in these outcomes over time and to identify subject characteristics associated with recovery.

\section{METHODS}

\section{Design and Procedures}

This was an inception cohort study of 33 adults with a unilateral non-cerebellar stroke. Results of other aspects of the study have been reported elsewhere. ${ }^{22,23}$ Volunteers were included in the study if they: 1) were medically stable and free of major cardiovascular and musculoskeletal problems as indicated by physician approval for study participation, 2) had lower extremity motor impairment, as indicated by a score of 228 out of 34 points on the Fugl-Meyer lower extremity motor scale (FM-leg), ${ }^{24} 3$ ) were able to live independently in the community prior to the stroke, 4) were able to read and understand English and follow 3step commands, 5) had adequate vision, hearing, and sitting balance for completing the study protocol, and 6) lived within a 50-mile radius and were willing to return to the laboratory for monthly testing. Exclusion criteria were: 1) history of previous strokes or other neurologic diseases or disorders, 2) terminal illness, and 3) pain, limited motion, or weakness in the non-paretic lower extremity that affected performance of ADL (by selfreport). The study received Biomedical Institutional Review Board approval, and informed consent was obtained from all participants prior to testing.

Baseline testing was performed while the participant was hospitalized, and included assessment of visual perception and examination of paretic lower extremity motor function. Subsequently, participants were tested in the laboratory one time per month from 1 to 6 months post stroke. At each test session, paretic lower extremity loading (PLEL) during STS, gait speed, and physical function were measured by the same examiner. At each test session, patients were also asked about the amount of therapy received (number of hours per week) in the prior month. 


\section{Measurements}

Baseline tests included the letter and star cancellation subtests of the Behavioral Inattention Test (to assess visuospatial neglect) ${ }^{25}$ and the FM-leg test. In the majority of previous studies, neglect has been addressed in general terms, without classifying it into different subtypes. ${ }^{26}$ The present study focused on visual neglect, which has been suggested to play a major role in disability and handicap in individuals with stroke. ${ }^{27}$ Letter and star cancellation subtests were selected because they can be administered in less than 5 minutes and, in one study, identified $74 \%$ of neglect patients with no false positives. ${ }^{25}$

The FM-leg includes 6 items assessing reflex activity, voluntary movement in and out of synergy patterns, and coordination/speed of movement of the paretic lower extremity. High intra- and inter-rater reliability coefficients have been reported for use of the FM with patients less than 6 months post-stroke. ${ }^{28,29}$

Outcomes-PLEL was measured using two $40-\mathrm{cm} \times 60-\mathrm{cm}$ force platforms ${ }^{\mathrm{a}}$ mounted side-by-side in the floor which recorded ground reaction forces (GRFs) during the STS task. A standard wooden chair without armrests was positioned just behind the force platforms, and the participant was seated with one foot on each force platform. A paper tracing of each participant's feet was used to maintain consistent positioning across sessions. The participant completed four test trials of the STS task, with instructions to come to standing as quickly as possible without feeling unsafe. The peak vertical GRF beneath the paretic lower extremity during STS was determined and expressed as a proportion of the participant's body weight.

GS was determined from standardized administration of two test trials of the 10-meter walk test, ${ }^{30}$ with the participant instructed to walk at a usual, comfortable pace. GS is a global measure of physical functioning that has high test-retest reliability and correlates with a number of other measures of walking ability after stroke. ${ }^{31,32}$ For PLEL and GS, a response score of 0 was used when the participant was unable to perform the task without physical assistance from another person.

The PFI, ${ }^{21}$ a self-report instrument comprised of 10 questions about limitations in higher level physical activities (e.g., carrying groceries, climbing stairs), was administered by interview. Possible scores range from 0 to 100, with 100 indicating full independence. The PFI has high internal consistency and test-retest reliability, ${ }^{33,34}$ and has been validated for individuals with stroke. ${ }^{34}$

\section{Statistical Analysis}

To assess recovery over time for each repeated outcome (PLEL, GS, PFI), we estimated linear, mixed models ${ }^{35,36}$ having correlated random intercepts and slopes. Restricted maximum likelihood estimation via PROC MIXED in SAS $9.2^{\mathrm{b}}$ was used to perform the analyses. One participant had missing values for star and letter cancellation scores. These values were imputed by using single conditional mean imputation from a linear model for

\footnotetext{
${ }^{a}$ Bertec Corporation, 6171 Huntley Rd, Columbus, OH 43229

bSAS Institute, Inc., 100 SAS Campus Dr., Cary, NC 27513
} 
the bivariate outcome of star and letter cancellation using race, age, and baseline FM-leg score as predictors. Our model included session (month 1-6) and two mean-centered exposure variables, which were FM-leg score and star cancellation score. Additionally, control variables of gender, race and baseline age centered at its mean were examined for significance in an initial model; any one of them with p-value $>0.15$ for all three outcomes was excluded from all models, and otherwise retained in all three models. Anticipating that the two measures of neglect would be collinear, star cancellation was chosen a priori for inclusion over letter cancellation because the literature suggested it to be the most useful test for detecting visual neglect in the acute stage after stroke. ${ }^{37}$ The model also included the interactions of session with FM-leg score and star cancellation score to determine whether the degree of baseline impairment affected rate of recovery. These were retained in the final model regardless of statistical significance because these effects addressed the primary objective of testing for differential recovery rates.

Sensitivity Analyses-In order to examine potential effects of intervention on stroke recovery, expanded models that included three additional terms, the linear and quadratic effects of amount of physical therapy and the interaction of session and the linear term for amount of physical therapy, were estimated for each outcome. Because the statistical properties of regression parameter estimators would begin to deteriorate with increasing model degrees-of-freedom, given our small sample size, no other interactions or control variables were considered for inclusion. The Kenward-Roger small-sample degrees-offreedom correction ${ }^{38}$ was used in hypothesis testing to maintain the Type I error at the specified level of statistical significance of 0.05. Additional details about the statistical analyses can be found in the Appendix (Supplemental Tables I-VII).

\section{RESULTS}

A total of 78 individuals underwent screening, and 45 were found to be eligible. Of these, 8 declined participation, 2 were excluded because of deteriorating cognitive status, and 2 were lost to follow-up. The remaining 33 individuals enrolled in the study, and their baseline characteristics are presented in Table 1.

A majority (70\%) of the participants had right hemisphere stroke (left-sided paresis), and $73 \%$ of these individuals had evidence of unilateral visuospatial neglect, based on letter or star cancellation test scores (cut-off value $=32$ for letter cancellation; 51 for star cancellation). In contrast, only 1 of the 10 participants with right-sided paresis scored at or below the cut-off value on either cancellation test. As expected, star cancellation score was highly correlated with letter cancellation score $(r=0.64)$. Table 2 shows the crossclassification of the quartiles for baseline star cancellation score and FM-leg score, which indicates a weak relationship between these two baseline measures. Individuals who had more severe visuospatial neglect (lower star cancellation test scores) did not tend to have poorer paretic lower extremity motor function (lower FM-leg scores).

The study achieved excellent follow-up. Among a possible total of 198 participant-visits (33*6), only 15 participant-visits were missing $(7.5 \%)$, with an average of 5.6 visits attended per participant. For PLEL, eight participants (24.2\%) were unable to perform the STS task at 
one or more visits, but only two participants were never able to perform the task. For GS, eight participants $(24.2 \%)$ were unable to complete the 10-meter walk at one or more visits, but only one participant was never able to perform the task. Mean values for PLEL, GS, and PFI at each visit are shown in Table 3 and indicate general improvement over time.

All participants received usual medical care and rehabilitation during the study. Amount of physical therapy (PT) received decreased over time (Table 3). At the first testing session, $42 \%$ of subjects $(\mathrm{N}=14)$ were in inpatient rehabilitation and $76 \%$ reported receiving PT in the prior month. By session 2, only one subject was in inpatient rehabilitation and $74 \%$ of subjects reported receiving PT in the prior month. By the last session, 38\% of subjects reported receiving PT in the prior month. The amount of PT received (by participant selfreport) in the prior month decreased from a mean (SD) of 4.9 (4.0) hours per week at the first session to 0.9 (1.2) hours per week at the last session.

Figure 1 shows the vertical GRFs beneath the paretic and non-paretic lower extremities for performance of one trial of the STS task by a participant with stroke in panel A and, for comparison, by an individual with no history of stroke or other pathology in panel B. The individual with stroke demonstrated marked asymmetry, with much less loading of the paretic as compared to the non-paretic lower extremity. It is important to note that the sum of the peak vertical GRFs during STS exceeds body weight in individuals with no known pathology, with a value on the order of $116 \%$ of body weight. ${ }^{39}$ Thus, the proportion of body weight beneath each lower extremity may reach a peak of approximately 0.60 (assuming symmetry between the two lower extremities), returning to 0.50 only after the individual achieves steady state standing at the end of the STS task.

\section{Linear Mixed Models Analyses}

Table 4 presents the results of the final linear, mixed models examining the association between session and outcomes, controlling for patient characteristics. Race/ethnicity was excluded from the final models because preliminary analyses showed that this variable had little effect on the outcomes in the presence of the other variables in the models $(p>0.50)$.

A statistically significant positive association was found between session and all three outcomes, indicating that participants, on average, improved over time (Table 4). For the PLEL outcome, the interactions of session with baseline FM-leg and baseline star cancellation suggest that rate of recovery for this outcome differed for different levels of these baseline scores. The mean recovery rate for PLEL decreased by 0.002 for every unit increase in baseline FM-leg score ( $\mathrm{p}=0.012)$, controlling for all other variables. In other words, participants with greater initial impairment in paretic lower extremity motor function had a significantly faster recovery rate in their ability to load the extremity during STS. The mean recovery rate for PLEL increased by 0.001 for every unit increase in baseline star cancellation, indicating a trend $(p=0.063)$ toward faster recovery for participants with better visual perception. For all three models, the interactions of session with age or gender were not significant (not shown), indicating that these variables did not influence rate of recovery.

Table 4 also indicates that, on average, women and older individuals had lower GS relative to men and younger individuals, and participants with higher baseline FM-leg scores had 
higher PLEL and GS scores. There also were trends toward higher PFI scores for men and younger participants and toward faster gait speeds for individuals with higher star cancellation scores.

Using the fitted model results in Table 4, mean differences in performance scores at the 6 month session were estimated based on differences in the baseline FM-leg and star cancellation scores (Table 5). For example, an increase in baseline FM-leg score of 10 (difference between the values of the first and third quartiles) corresponded to an increase in PLEL at 6 months of 0.0115 (i.e., $1.2 \%$ body weight increase in peak vertical GRF beneath the paretic lower extremity during STS; $p=0.014)$. Similarly, holding all other factors fixed, an increase in baseline star cancellation score of 9 (difference between the values of the first and third quartiles), corresponded to an increase in PLEL at 6 months of 0.0067 (i.e., $0.7 \%$ body weight increase in peak vertical GRF beneath the paretic lower extremity during STS; $\mathrm{p}=0.013$ ). A statistically significant difference also was found for GS, with a 10-point increase in baseline FM-leg score corresponding to a $0.04 \mathrm{~m} / \mathrm{sec}$ increase in GS at 6 months.

Figures 2 and 3 present the model-predicted PLEL values by session, illustrating the patterns of subject-specific recovery rates. Fixing star cancellation score at its mean, the subjectspecific linear trend predictions are presented in the four panels of Figure 2 according to quartiles of baseline FM-leg score. Individuals with the lowest baseline FM-leg scores (Figure 2, panel A), tended to have the lowest initial values, the greatest predicted recovery rates, and lower 6-month values for PLEL relative to individuals with higher FM-leg scores. Figure 3 presents the subject 265 specific linear trend predictions according to quartiles of baseline star cancellation score, with baseline FM-leg score fixed at its mean. Subjects with star cancellation scores in the lowest quartile (panel A) tended to have negative or small positive predicted recovery rates for PLEL, while those in the other quartiles tended to have higher predicted recovery rates.

Our sensitivity analyses indicated that amount of PT had little impact on our findings regarding PLEL and GS recovery (Supplemental Tables IV and V). None of the therapy terms was significant, nor did they significantly alter the point estimates of our final models. The addition of therapy variables did alter the PFI recovery findings slightly, though the point estimates were imprecise with wide confidence intervals (Supplemental Table VI). When all three therapy terms were added (therapy hours, therapy hours squared, and session*therapy hours) to the PFI model, the rate of recovery over time diminished, suggesting that amount of therapy received has some impact on PFI recovery. The parameter estimates for therapy hours were also negative in most of the models, though mostly nonsignificant, suggesting that individuals who received more therapy had greater initial impairments. Finally, the parameter estimate for session*PT hours was positive in all of the models suggesting rate of recovery may be greater with more PT hours.

\section{DISCUSSION}

Participants in our study generally improved in paretic lower extremity loading, gait speed, and self-reported physical function during the period from 1 to 6 months after stroke. Baseline paretic lower extremity motor function as measured by FM-leg score emerged as 
an important factor affecting post-stroke performance. Individuals with poorer paretic lower extremity motor function (lower FM-leg score) at baseline had faster rates of recovery than those with higher FM-leg scores. This likely is the result of a ceiling effect, with individuals with high baseline FM-leg scores having limited range for improvement in PLEL values.

FM-leg scores also were associated with PLEL values and GS over the 6- month period. Those with higher FM-leg scores had higher PLEL values and faster GS. These results make sense clinically, as FM-leg scores reflect paretic lower extremity muscle strength and movement outside of synergy patterns. Paretic lower extremity muscle strength is needed for weight-bearing support when standing up from a chair and during the stance phase of gait, and capacity for movement outside of stereotypical synergies may be critical for controlling the limb during the swing phase of gait. Other researchers have reported that patients with stroke who have less motor impairment of the paretic leg, as compared to those with more severe impairment, show greater weight-bearing symmetry in standing. ${ }^{40}$ Our results also are consistent with previous reports in the literature suggesting that FM-leg score is correlated with other functional measures. ${ }^{14,15}$

Visual perception as measured by baseline star cancellation score also was identified as having an effect on recovery. The incidence of unilateral visuospatial neglect among study participants was high, but consistent with reports in the literature. ${ }^{41,42}$ Individuals with the most severe neglect, who scored in the lowest quartile on star cancellation, had lower rates of recovery for the ability to bear weight through the paretic leg when standing up from a chair. There also was a trend toward a positive association between star cancellation score and post-stroke GS. Previous researchers have found a negative association between severity of neglect and function, and some have reported a slower rate of recovery for individuals with neglect. ${ }^{41-43}$ Our study is the first to provide evidence that neglect slows recovery of the ability to bear weight through the paretic lower extremity for symmetrical performance of STS.

PLEL was the only study outcome for which recovery rate was affected by our baseline measures. PLEL is a direct measure of paretic lower extremity loading and is not likely to be influenced by compensatory movements. PLEL, therefore, most likely reflects true neurological recovery. PLEL also was our most precise outcome measure, involving laboratory recording of forces beneath the feet. Our findings suggest that PLEL may be an appropriate focus of intervention, especially for those with marked impairments in paretic lower extremity motor function or visual perception. Although patients may regain independence in STS transfers and other functional activities by compensating with the nonparetic lower extremity, previous researchers have shown that such compensatory strategies are attention-demanding. ${ }^{40,44}$ This type of compensation may be less than optimal for performance of challenging, dynamic tasks in complex environments.

In addition to the correlation with baseline FM-leg score, post-stroke GS was correlated with age and gender. Our findings of slower GS for older as compared to younger participants and for women as compared to men make sense intuitively, and also have some support in the literature. Slowing of GS with increasing age has been reported in previous studies of 
healthy older adults. ${ }^{45,46}$ In the general population, men walk faster than women at every age, with more marked differences after 55 years of age. ${ }^{47}$

Although session was associated with participants' PFI scores, indicating improvement over time, our baseline clinical measures were not. The items on the PFI include several very challenging tasks, such as climbing stairs and walking more than a mile. Some items also involve upper extremity motor function, such as lifting or carrying groceries. Limitations in performance of these activities may result from a multitude of factors not addressed in this study, ranging from poor upper extremity motor function to lack of caregiver and/or environmental supports.

\section{Study Limitations}

This study had a relatively small sample size, which limited the number of predictor variables that could be included in the analyses and constrained whether or how PLEL and GS were scored when an individual required physical assistance from another person to perform the task. Had the study been a large one, two-part mixed effects models for semicontinuous data could have been employed. ${ }^{43}$ The first part would have modeled the dichotomous outcome of whether the individual could perform the task independently. The second part would specify a linear mixed model similar to the one used in this article for the non-zero outcome values, that is, given the individual could perform the task without physical assistance. Such a model proved unfeasible for this small study; estimates could not be obtained because the models would not converge. Instead, scores of zero were assigned in these instances. This decision was based on our view that a score of zero was a meaningful representation of the individual's capacity for independent performance, and was more realistic than, for example, treating the value as missing. Treating such values as missing would have been like imputing a non-zero value for them from the individual's observed non-zero scores to the extent that the intra-individual correlation is strong enough to impose similarity between the observed scores and the indeterminable ones.

The small sample size of our study also limited the statistical power to detect associations between the exposure effects and outcomes. In the case of PFI, the post-hoc power to detect the observed difference of 1.014 in PFI with a one unit increase in baseline FM-leg (Table 4) was 0.42 , whereas the minimum detectable difference based on 0.80 power and two-sided 0.05 significance tests was 2.0 (see Appendix).

Definitive conclusions concerning the influence of the amount of PT on recovery were also not possible in this study because of the limited sample size. The variable for amount of therapy reflected only the amount of PT participants received, with no consideration for other rehabilitation therapies such as occupational therapy. Observed results indicated trends consistent with expectations, namely that participants with greater impairment may tend to receive more therapy, and participants who receive more therapy may tend to have faster recovery rates. These tentative results support the need for a larger study examining the effects of the type of therapy, the amount of therapy, and the composition of the therapy on recovery of function after stroke. 
An additional limitation of the present study is that, given the composition of the study population, the results may not be generalizable to the broader population of individuals post-stroke. The sample included a high percentage of younger individuals $(45.5 \%<55$ years of age) and of individuals with left-sided hemiparesis (70\%). It is important to note, however, that the incidence of stroke in people under 55 years of age is increasing, from $12.9 \%$ of all strokes in $1993 / 1994$ to $18.6 \%$ in $2005 .{ }^{48}$ Given this trend, and the associated significant decrease in the mean age at time of stroke from 71.2 years in 1993/1994 to 69.2 years in $2005,{ }^{48}$ the subpopulation of younger people with stroke is worthy of further study.

\section{CONCLUSIONS}

Baseline stroke severity, measured by paretic lower extremity motor function and visual perception, is associated with the rate of recovery of paretic lower extremity loading during sit387 to-stand in the first 6 months after stroke. Individuals with more limited motor function recover at a faster rate, while those with neglect recover at a slower rate.

\section{Supplementary Material}

Refer to Web version on PubMed Central for supplementary material.

\section{Acknowledgments}

Sources of funding: NIH/NICHD grant R03 HD43907

\section{Abbreviations}

$\begin{array}{ll}\text { ADL } & \text { activities of daily living } \\ \text { FM-leg } & \text { Fugl-Meyer lower extremity motor scale } \\ \text { GRF } & \text { ground reaction force } \\ \text { GS } & \text { self-selected gait speed } \\ \text { PFI } & \text { Physical Functioning Index } \\ \text { PLEL } & \text { paretic lower extremity loading } \\ \text { STS } & \text { sit-to-stand }\end{array}$

\section{References}

1. Norrving B, Kissela B. The global burden of stroke and need for a continuum of care. Neurology. 2013; 80(3 Suppl 2):S5-S12. [PubMed: 23319486]

2. Go AS, Mozaffarian D, Roger VL, et al. Heart disease and stroke statistics--2013 update: A report from the American Heart Association. Circulation. 2013; 127(1):e6-e245. [PubMed: 23239837]

3. Bonita R, Solomon N, Broad JB. Prevalence of stroke and stroke-related disability. Estimates from the Auckland stroke studies. Stroke. 1997; 28(10):1898-1902. [PubMed: 9341692]

4. Barak S, Duncan PW. Issues in selecting outcome measures to assess functional recovery after stroke. NeuroRx. 2006; 3(4):505-524. [PubMed: 17012065]

5. Kollen B, Kwakkel G, Lindeman E. Longitudinal robustness of variables predicting independent gait following severe middle cerebral artery stroke: A prospective cohort study. Clin Rehabil. 2006; 20(3):262-268. [PubMed: 16634346] 
6. Kwakkel G, Kollen B, Lindeman E. Understanding the pattern of functional recovery after stroke: Facts and theories. Restor Neurol Neurosci. 2004; 22(3-5):281-299. [PubMed: 15502272]

7. Verheyden G, Nieuwboer A, De Wit L, et al. Time course of trunk, arm, leg, and functional recovery after ischemic stroke. Neurorehabil Neural Repair. 2008; 22(2):173-179. [PubMed: 17876069]

8. Toschke AM, Tilling K, Cox AM, Rudd AG, Heuschmann PU, Wolfe CD. Patient-specific recovery patterns over time measured by dependence in activities of daily living after stroke and post-stroke care: The south London stroke register (SLSR). Eur J Neurol. 2010; 17(2):219-225. [PubMed: 19682061]

9. Nudo RJ. Neural bases of recovery after brain injury. J Commun Disord. 2011; 44(5):515-520. [PubMed: 21600588]

10. Bohannon RW, Lee N, Maljanian R. Postadmission function best predicts acute hospital outcomes after stroke. Am J Phys Med Rehabil. 2002; 81(10):726-730. [PubMed: 12362111]

11. Pettersen R, Dahl T, Wyller TB. Prediction of long-term functional outcome after stroke rehabilitation. Clin Rehabil. 2002; 16(2):149-159. [PubMed: 11911513]

12. Chae J, Johnston M, Kim H, Zorowitz R. Admission motor impairment as a predictor of physical disability after stroke rehabilitation. Am J Phys Med Rehabil. 1995; 74(3):218-223. [PubMed: 7779333]

13. Jorgensen HS, Nakayama H, Raaschou HO, Olsen TS. Recovery of walking function in stroke patients: The Copenhagen stroke study. Arch Phys Med Rehabil. 1995; 76(1):27-32. [PubMed: 7811170]

14. Patel AT, Duncan PW, Lai SM, Studenski S. The relation between impairments and functional outcomes poststroke. Arch Phys Med Rehabil. 2000; 81(10):1357-1363. [PubMed: 11030501]

15. Kollen B, van de Port I, Lindeman E, Twisk J, Kwakkel G. Predicting improvement in gait after stroke: A longitudinal prospective study. Stroke. 2005; 36(12):2676-2680. [PubMed: 16282540]

16. Burnett DR, Campbell-Kyureghyan NH, Cerrito PB, Quesada PM. Symmetry of ground reaction forces and muscle activity in asymptomatic subjects during walking, sit-to-stand, and stand-to-sit tasks. J Electromyogr Kinesiol. 2011; 21(4):610-615. [PubMed: 21493090]

17. Boonstra MC, Schwering PJ, De Waal Malefijt MC, Verdonschot N. Sit-to-stand movement as a performance-based measure for patients with total knee arthroplasty. Phys Ther. 2010; 90(2):149156. [PubMed: 20007664]

18. Lomaglio MJ, Eng JJ. Muscle strength and weight-bearing symmetry relate to sit-to-stand performance in individuals with stroke. Gait Posture. 2005; 22(2):126-131. [PubMed: 16139747]

19. de Haart M, Geurts AC, Dault MC, Nienhuis B, Duysens J. Restoration of weight-shifting capacity in patients with postacute stroke: A rehabilitation cohort study. Arch Phys Med Rehabil. 2005; 86(4):755-762. [PubMed: 15827928]

20. Green J, Forster A, Young J. Reliability of gait speed measured by a timed walking test in patients one year after stroke. Clin Rehabil. 2002; 16(3):306-314. [PubMed: 12017517]

21. Ware JE Jr, Sherbourne CD. The MOS 36-item short-form health survey (SF-36). I. conceptual framework and item selection. Med Care. 1992; 30(6):473-483. [PubMed: 1593914]

22. Mercer VS, Freburger JK, Chang SH, Purser JL. Measurement of paretic- lower-extremity loading and weight transfer after stroke. Phys Ther. 2009; 89(7):653-664. [PubMed: 19465370]

23. Mercer VS, Freburger JK, Chang SH, Purser JL. Step test scores are related to measures of activity and participation in the first 6 months after stroke. Phys Ther. 2009; 89(10):1061-1071. [PubMed: 19661158]

24. Fugl-Meyer AR, Jaasko L, Leyman I, Olsson S, Steglind S. The post-stroke hemiplegic patient. 1. A method for evaluation of physical performance. Scand J Rehabil Med. 1975; 7(1):13-31. [PubMed: 1135616]

25. Halligan P, Wilson B, Cockburn J. A short screening test for visual neglect in stroke patients. Int Disabil Stud. 1990; 12(3):95-99. [PubMed: 2096121]

26. Jehkonen M, Laihosalo M, Kettunen JE. Impact of neglect on functional outcome after stroke: A review of methodological issues and recent research findings. Restor Neurol Neurosci. 2006; 24(4-6):209-215. [PubMed: 17119299] 
27. Kalra L, Perez I, Gupta S, Wittink M. The influence of visual neglect on stroke rehabilitation. Stroke. 1997; 28(7):1386-1391. [PubMed: 9227688]

28. Sanford J, Moreland J, Swanson LR, Stratford PW, Gowland C. Reliability of the fugl-meyer assessment for testing motor performance in patients following stroke. Phys Ther. 1993; 73(7): 447-454. [PubMed: 8316578]

29. Duncan PW, Propst M, Nelson SG. Reliability of the Fugl-Meyer assessment of sensorimotor recovery following cerebrovascular accident. Phys Ther. 1983; 63(10):1606-1610. [PubMed: 6622535]

30. Taylor D, Stretton CM, Mudge S, Garrett N. Does clinic-measured gait speed differ from gait speed measured in the community in people with stroke? Clin Rehabil. 2006; 20(5):438-444. [PubMed: 16774095]

31. Holden MK, Gill KM, Magliozzi MR, Nathan J, Piehl-Baker L. Clinical gait assessment in the neurologically impaired. reliability and meaningfulness. Phys Ther. 1984; 64(1):35-40. [PubMed: 6691052]

32. Mudge S, Stott NS. Timed walking tests correlate with daily step activity in persons with stroke. Arch Phys Med Rehabil. 2009; 90(2):296-301. [PubMed: 19236983]

33. Brazier JE, Harper R, Jones NM, et al. Validating the SF-36 health survey questionnaire: New outcome measure for primary care. BMJ. 1992; 305(6846):160-164. [PubMed: 1285753]

34. Anderson C, Laubscher S, Burns R. Validation of the short form 36 (SF-36) health survey questionnaire among stroke patients. Stroke. 1996; 27(10):1812-1816. [PubMed: 8841336]

35. Laird NM, Ware JH. Random-effects models for longitudinal data. Biometrics. 1982; 38(4):963974. [PubMed: 7168798]

36. Holditch-Davis D, Edwards LJ. Modeling development of sleep-wake behaviors. II. Results of two cohorts of preterms. Physiol Behav. 1998; 63(3):319-328. [PubMed: 9469722]

37. Bailey MJ, Riddoch MJ, Crome P. Evaluation of a test battery for hemineglect in elderly stroke patients for use by therapists in clinical practice. NeuroRehabilitation. 2000; 14(3):139-150. [PubMed: 11455076]

38. Kenward MG, Roger JH. Small sample inference for fixed effects from restricted maximum likelihood. Biometrics. 1997; 53(3):983-997. [PubMed: 9333350]

39. Etnyre B, Thomas DQ. Event standardization of sit-to-stand movements. Phys Ther. 2007; 87(12): 1651-1666. [PubMed: 17940102]

40. Roerdink M, Geurts AC, de Haart M, Beek PJ. On the relative contribution of the paretic leg to the control of posture after stroke. Neurorehabil Neural Repair. 2009; 23(3):267-274. [PubMed: 19074685]

41. Di Monaco M, Schintu S, Dotta M, Barba S, Tappero R, Gindri P. Severity of unilateral spatial neglect is an independent predictor of functional outcome after acute inpatient rehabilitation in individuals with right hemispheric stroke. Arch Phys Med Rehabil. 2011; 92(8):1250-1256. [PubMed: 21807144]

42. Wee JY, Hopman WM. Comparing consequences of right and left unilateral neglect in a stroke rehabilitation population. Am J Phys Med Rehabil. 2008; 87(11):910-920. [PubMed: 18936556]

43. Katz N, Hartman-Maeir A, Ring H, Soroker N. Functional disability and rehabilitation outcome in right hemisphere damaged patients with and without unilateral spatial neglect. Arch Phys Med Rehabil. 1999; 80(4):379-384. [PubMed: 10206598]

44. de Haart M, Geurts AC, Huidekoper SC, Fasotti L, van Limbeek J. Recovery of standing balance in postacute stroke patients: A rehabilitation cohort study. Arch Phys Med Rehabil. 2004; 85(6): 886-895. [PubMed: 15179641]

45. Bohannon RW. Comfortable and maximum walking speed of adults aged 20-79 years: Reference values and determinants. Age Ageing. 1997; 26(1):15-19. [PubMed: 9143432]

46. Schimpl M, Moore C, Lederer C, et al. Association between walking speed and age in healthy, free-living individuals using mobile accelerometry--a cross-sectional study. PLoS One. 2011; 6(8):e23299. [PubMed: 21853107]

47. Tolea MI, Costa PT, Terracciano A, et al. Sex-specific correlates of walking speed in a wide ageranged population. J Gerontol B Psychol Sci Soc Sci. 2010; 65B(2):174-184. [PubMed: 20051464] 
48. Kissela BM, Khoury JC, Alwell K, et al. Age at stroke: Temporal trends in stroke incidence in a large, biracial population. Neurology. 2012; 79(17):1781-1787. [PubMed: 23054237] 

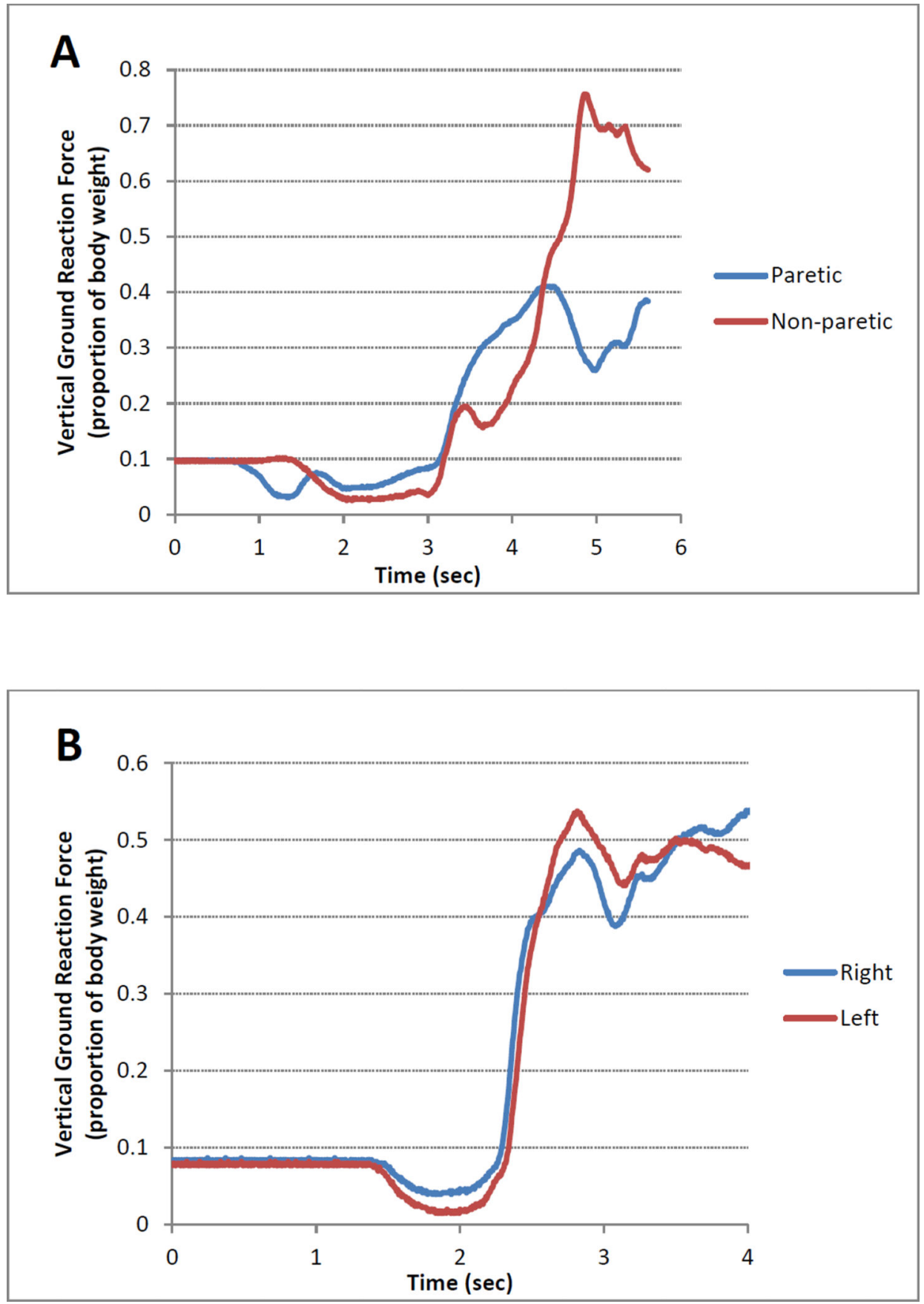

Figure 1.

Vertical ground reaction forces (expressed as a proportion of body weight) beneath the lower extremities during a representative trial of sit-to-stand by a participant with stroke (Panel A) and an individual with no history of stroke or other pathology (Panel B). 

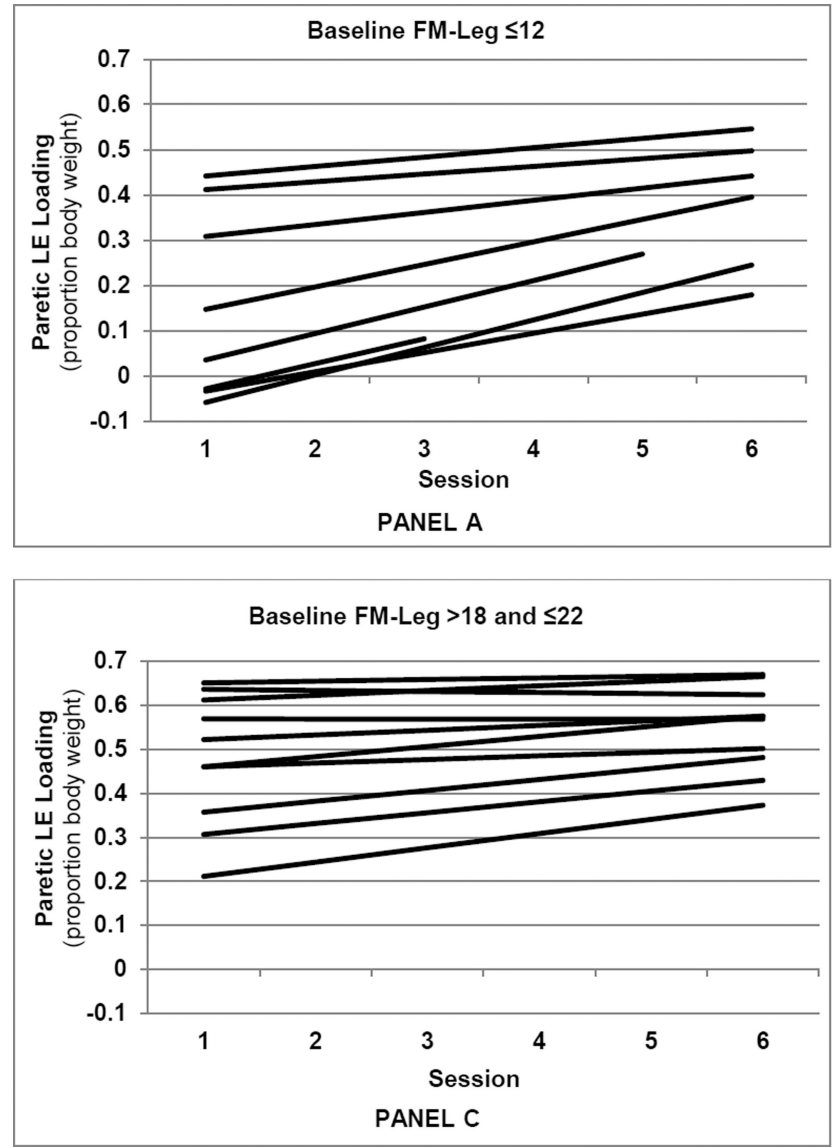
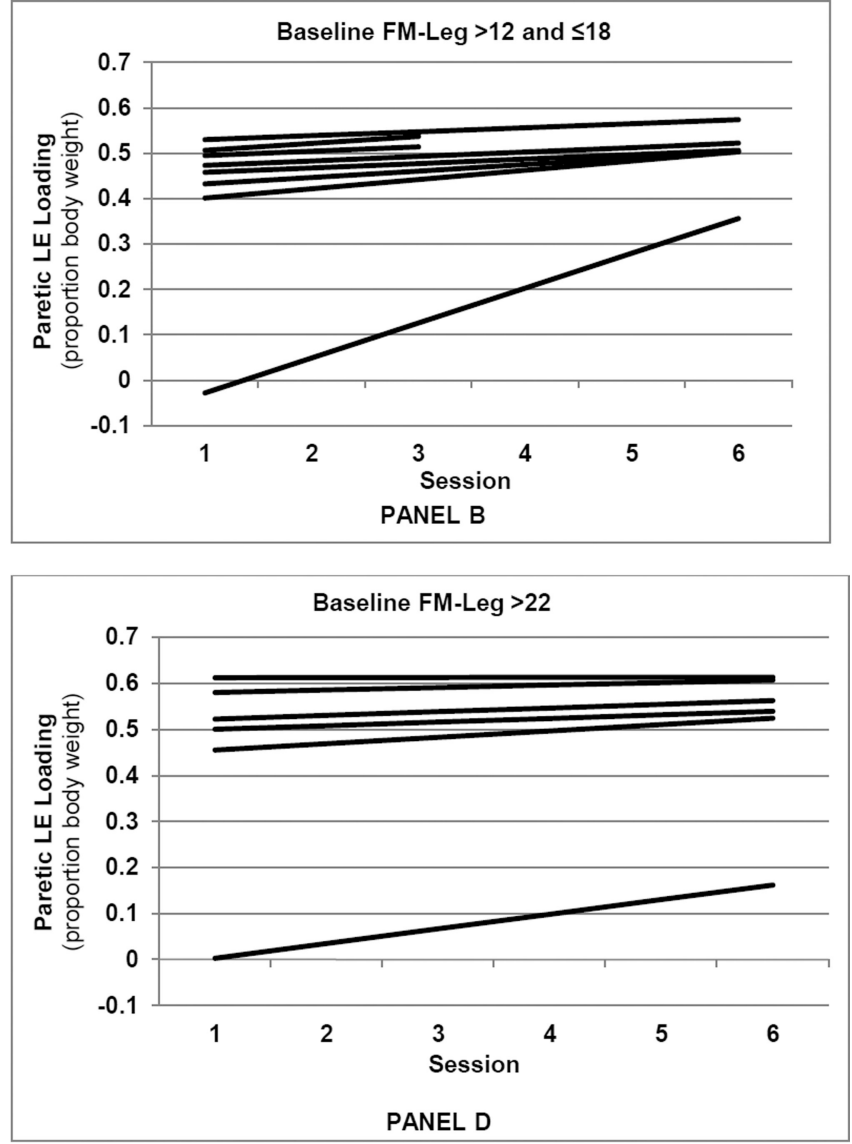

Figure 2.

Predicted paretic lower extremity loading (peak vertical ground reaction force beneath the paretic leg) by session for each subject, grouped according to baseline Fugl-Meyer score quartiles. Panels A through D represent the first through the fourth quartiles, respectively. 

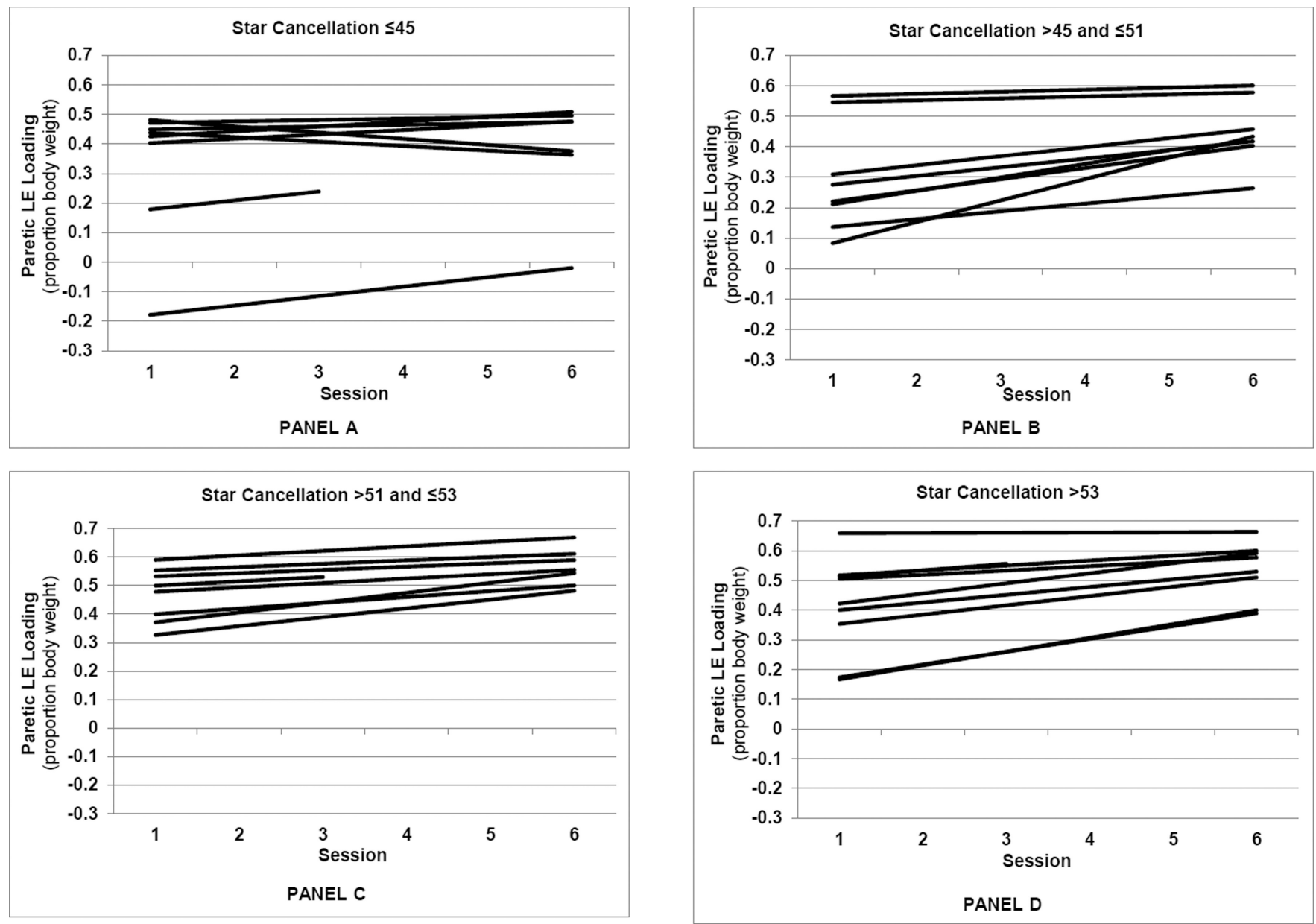

Figure 3.

Predicted paretic lower extremity loading (peak vertical ground reaction force beneath the paretic leg) by session for each subject, grouped according to baseline star cancellation score quartiles. Panels A through D represent the first through the fourth quartiles, respectively. 


\section{Table 1}

Baseline Participant Characteristics $(\mathrm{N}=33)$

\begin{tabular}{|c|c|}
\hline Variable & $\begin{array}{c}\text { Number (Percentage) or } \\
\text { Mean (Standard Deviation) [Range] }\end{array}$ \\
\hline \multicolumn{2}{|l|}{ Gender } \\
\hline - Female & $15(45.5 \%)$ \\
\hline - Male & $18(54.5 \%)$ \\
\hline \multicolumn{2}{|l|}{ Race } \\
\hline - White & $18(54.6 \%)$ \\
\hline - African-American & $14(42.4 \%)$ \\
\hline • Hispanic & $1(3.0 \%)$ \\
\hline Age (years) & $58.7(17.3)[24-97]$ \\
\hline$\bullet<55$ years & $15(45.5 \%)$ \\
\hline$\cdot \geq 55$ years & $18(54.5 \%)$ \\
\hline \multicolumn{2}{|l|}{ Side of paresis } \\
\hline • Right & $10(30 \%)$ \\
\hline - Left & $23(70 \%)$ \\
\hline \multicolumn{2}{|l|}{ Lesion type and location } \\
\hline - Ischemic - cortical (involving ACA, MCA, PCA, parieto-occipital region) & $17(51.5 \%)$ \\
\hline - Ischemic - subcortical (involving internal capsule, basal ganglia, thalamus, pons) & $8(24.2 \%)$ \\
\hline - Hemorrhagic - cortical (all in parietal region) & $3(9.1 \%)$ \\
\hline - Hemorrhagic - subcortical (involving basal ganglia, thalamus, periventricular region) & $5(15.2 \%)$ \\
\hline \multicolumn{2}{|l|}{ Presence of unilateral spatial neglect ${ }^{*}$} \\
\hline - Yes & $17(53.1 \%)$ \\
\hline • No & $15(46.9 \%)$ \\
\hline Fugl-Meyer lower extremity motor scale & $17.8(6.2)[7-28]$ \\
\hline Star cancellation & $47.8(9.6)[10-54]$ \\
\hline Letter cancellation & $32.7(8.7)[6-40]$ \\
\hline
\end{tabular}

$\mathrm{ACA}=$ anterior cerebral artery; $\mathrm{MCA}=$ middle cerebral artery; $\mathrm{PCA}=$ posterior cerebral artery

* As determined by a score of $₫ 1$ on the star cancellation test or $\_2 \mathrm{n}$ the letter cancellation test; $\mathrm{N}=32$ for this measure (data missing for one participant with left-sided paresis) 


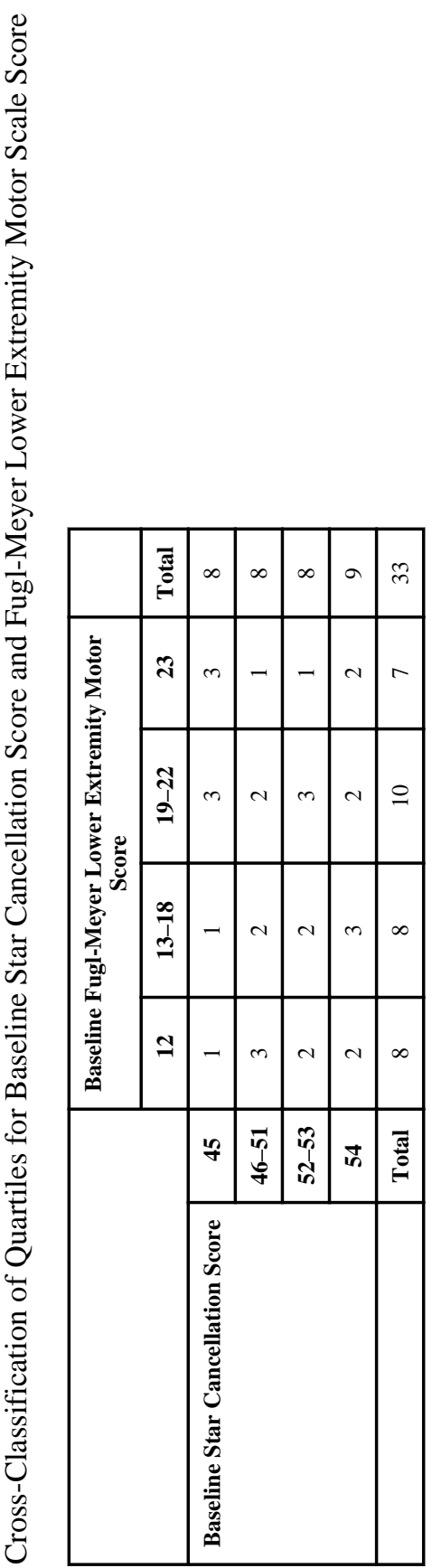

Arch Phys Med Rehabil. Author manuscript; available in PMC 2015 August 01. 


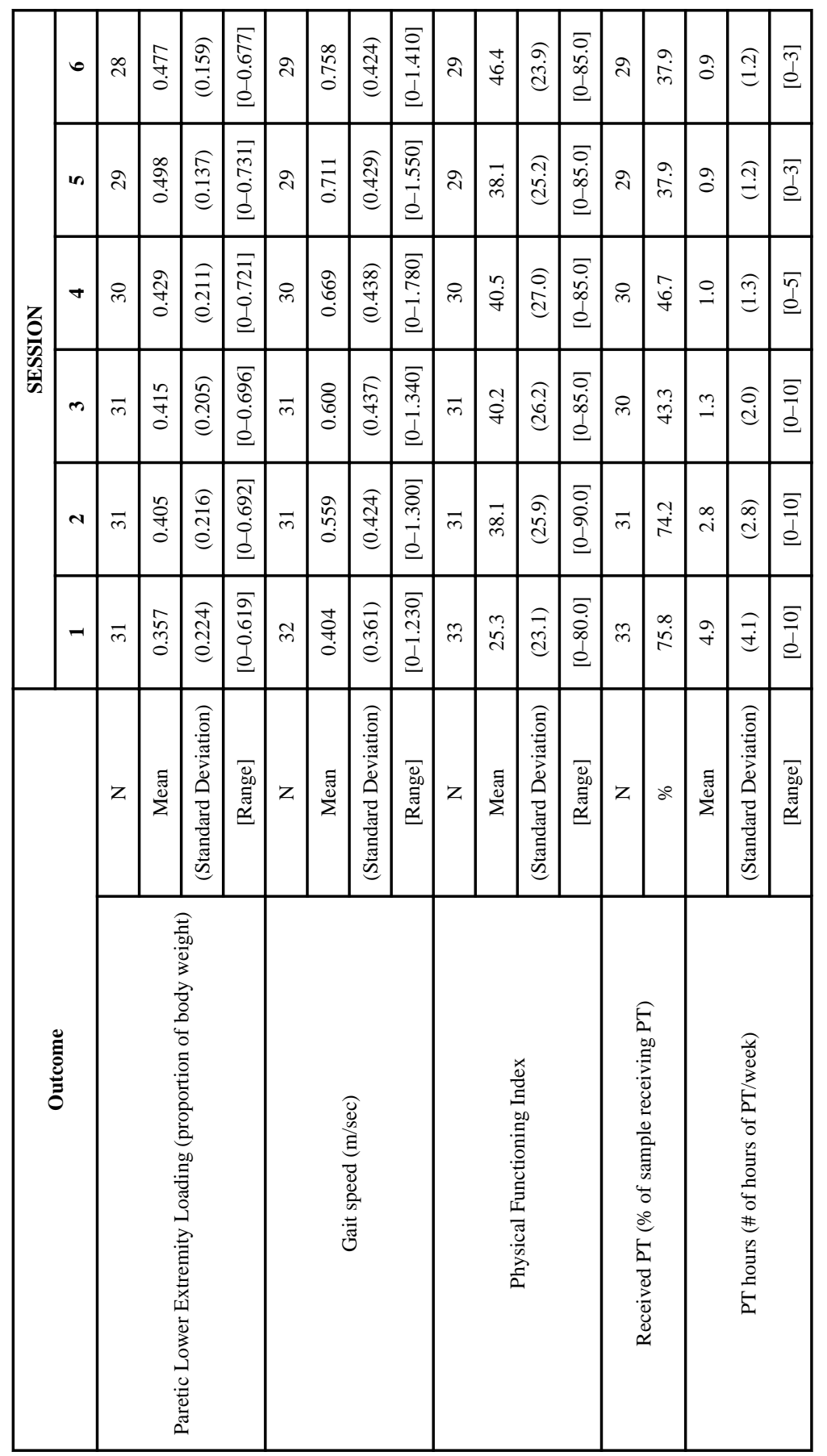


Table 4

Fixed Effects Estimates (SE) of Session and Patient Characteristics on Outcomes

\begin{tabular}{|c|l|l|l|}
\hline Effect & $\begin{array}{l}\text { Paretic Lower } \\
\text { Extremity Loading }\end{array}$ & Gait Speed & $\begin{array}{l}\text { Physical } \\
\text { Functioning Index }\end{array}$ \\
\hline Session & $0.0214(0.0047)^{* * *}$ & $0.0610(0.0077)^{* * *}$ & $2.979(0.687)^{* * *}$ \\
\hline Session $^{*}$ Baseline Fugl-Meyer & $-0.0021(0.0008)^{* *}$ & $0.0002(0.0013)$ & $0.053(0.115)$ \\
\hline Session $^{*}$ Star Cancellation & $0.0010(0.0005)^{*}$ & $-0.0005(0.0008)$ & $0.006(0.073)$ \\
\hline Female Gender & $-0.0090(0.0548)$ & $-0.2795(0.1074)^{* *}$ & $-14.651(7.890)^{*}$ \\
\hline Age & $-0.0023(0.0014)$ & $-0.0070(0.0028)^{* *}$ & $-0.372(0.208)^{*}$ \\
\hline Baseline Fugl-Meyer & $0.0240(0.0064)^{* * *}$ & $0.0345(0.0091)^{* * *}$ & $1.014(0.716)$ \\
\hline Star Cancellation & $0.0006(0.0040)$ & $0.0093(0.0053)^{*}$ & $-0.038(0.425)$ \\
\hline Intercept & $0.3610(0.0442)^{* * *}$ & $0.5251(0.0688)^{* * *}$ & $33.963(5.291)^{* * *}$ \\
\hline
\end{tabular}

$\mathrm{SE}=$ standard error.

$*$

$\mathrm{p}<0.10$

$* *$

$\mathrm{p}<0.05$

$* * *$

$\mathrm{p}<0.01$.

Note: All continuous covariates were centered on their means. 
Table 5

Estimated Mean Differences (SE) [95\% CI] in Performance Scores at Session 6 *

\begin{tabular}{|c|c|c|c|}
\hline Effect & $\begin{array}{c}\text { Paretic Lower } \\
\text { Extremity Loading }\end{array}$ & Gait Speed & $\begin{array}{l}\text { Physical Functioning } \\
\text { Index }\end{array}$ \\
\hline 10 unit $^{* *}$ change in baseline Fugl-Meyer, all other factors fixed & $\begin{array}{c}0.0115 \\
(0.0044) \\
{[0.0025,0.0205]}\end{array}$ & $\begin{array}{c}0.0355 \\
(0.0098) \\
{[0.0156,0.0555]}\end{array}$ & $\begin{array}{c}1.3315 \\
(0.7273) \\
{[-0.1517,2.8146]}\end{array}$ \\
\hline 9 unit ${ }^{* *}$ change in baseline star cancellation, all other factors fixed & $\begin{array}{c}0.0067 \\
(0.0025) \\
{[0.0153,0.0119]}\end{array}$ & $\begin{array}{c}0.0062 \\
(0.0058) \\
{[-0.0056,0.0181]}\end{array}$ & $\begin{array}{c}-0.0028 \\
(0.4295) \\
{[-0.8815,0.8758]}\end{array}$ \\
\hline
\end{tabular}

$\mathrm{SE}=$ standard error $; \mathrm{CI}=$ confidence interval.

* Based on linear mixed models reported in Table 3.

** Represents difference in scores from the first and third quartiles. 